\title{
Risk Perception and Concern among Brothers of Men with Prostate Carcinoma
}

\author{
Jennifer L. Beebe-Dimmer, M.P..., Ph.D. ${ }^{1,2}$ \\ David P. Wood, Jr., M.D. ${ }^{1}$ \\ Stephen B. Gruber, M.D., Ph.D. ${ }^{2,3}$ \\ Doug M. Chilson, B.S. ${ }^{3}$ \\ Kimberly A. Zuhlke, B.A. ${ }^{3}$ \\ Gina B. Claeys, B.S. ${ }^{3}$ \\ Kathleen A. Cooney, M.D. ${ }^{1,3}$ \\ ${ }^{1}$ Department of Urology, University of Michigan \\ Medical School, Ann Arbor, Michigan. \\ ${ }^{2}$ Department of Epidemiology, University of Mich- \\ igan School of Public Health, Ann Arbor, Michigan. \\ ${ }^{3}$ Department of Internal Medicine, University of \\ Michigan Medical School, Ann Arbor, Michigan.
}

Supported by Grant P50CA69568-06A1 from the National Institutes of Health.

Address for reprints: Jennifer L. Beebe-Dimmer, M.P.H., Ph.D., 7310 CCGC, 1500 East Medical Center Drive, Ann Arbor, Ml 48109-0946; Fax: (734) 615-2719; E-mail: jbeebe@med.umich.edu

Received September 24, 2003; revision received December 8, 2003; accepted January 12, 2004.
BACKGROUND. It is important for clinicians, researchers, and others who shape public health policy to understand the demographic correlates and psychologic factors that drive health behaviors, such as screening for early detection of cancer, particularly among individuals at high risk for developing the disease.

METHODS. One-hundred eleven men whose brothers were diagnosed with prostate carcinoma completed a computer-assisted telephone interview aimed to assess their perception of absolute risk and concern about developing prostate carcinoma over the next 10 years and across their lifetime. Comparisons were made between selected demographic, behavioral, family pedigree characteristics, and measures of perceived risk and concern.

RESULTS. The majority of men perceived their personal risk of developing prostate carcinoma to be $\geq 50 \%$. Men who at the time of the interview were younger than their affected brother were significantly more concerned about prostate carcinoma and perceived their risk to be higher than men who were older than their brother. Estimates of personal risk and concern were also uniformly higher among men with more than one first-degree relative affected with prostate carcinoma compared to men with only one affected first-degree relative. Risk perception and concern about an impending prostate carcinoma diagnosis were associated with the use of supplements marketed for prostate health.

CONCLUSIONS. The findings indicated that birth order in relation to a brother diagnosed with prostate carcinoma is significantly associated with risk perception and concern in unaffected family members. These results highlight the need for further study of the familial dynamics and characteristics that drive health behaviors and stress importance of public health education to inform men of personal risk assessment as well as the risks and benefits of screening. These studies ultimately can contribute to the success of strategies for the primary prevention and early detection of cancer. Cancer 2004;100:1537-44.

(C) 2004 American Cancer Society.

KEYWORDS: prostate carcinoma, family history, risk perception, concern.

$\mathbf{P}$ rostate carcinoma is the most common cancer affecting U.S. men, and it is estimated 220,900 new cases were diagnosed in 2003. It is the second leading cause of cancer mortality among men, behind lung carcinoma, with approximately 29,000 deaths expected this year. ${ }^{1}$ Despite the tremendous amount of research devoted to understanding the epidemiology of prostate carcinoma, to our knowledge relatively little is known regarding the etiology of the disease. Family history has been shown to be an important determinant of risk. Men with a family history of prostate carcinoma in a first-degree relative (father, brother, or son) are reported to be two to four times more likely to develop the disease compared with men with no such histo- 
ry. ${ }^{2}$ Higher relative risk estimates have been reported with a greater number of first-degree relatives affect$\mathrm{ed}^{3,4}$ and younger age at diagnosis. ${ }^{5,6}$ It has been estimated that $42 \%$ of prostate carcinoma cases may be attributable to hereditary factors. ${ }^{7}$ Given these statistics, it is particularly important to understand the motivation that drives men with a family history of prostate carcinoma to pursue health behaviors such as screening for early detection and the use of supplements or medications for chemoprevention. In the current study, we evaluated reported risk perception and concern about prostate carcinoma among men with one or more first-degree relatives with prostate carcinoma.

\section{MATERIALS AND METHODS \\ Subjects}

Subjects are all participants in the University of Michigan's Prostate Cancer Genetics Project (PCGP), a large, family-based study of inherited forms of prostate carcinoma. Initially, the PCGP enrolled families with two or more living affected family members in a first or second-degree relationship. However, enrollment criteria were later expanded to include men with prostate carcinoma diagnosed at age $\leq 55$ years who were without a family history.

A complete family history of cancer of any type in first-, second-, and third-degree relatives was obtained from all participants. For each reported case of prostate carcinoma in a family member, confirmation of diagnosis was attempted by contacting the relative, asking if he would also like to participate and if so, medical records were requested. If the family member was deceased, a diagnosis of prostate carcinoma was verified by receipt of a death certificate or by independent confirmation of the diagnosis by two or more relatives.

After enrollment, the affected men (probands) were phoned to ask them to contact unaffected brothers to become involved in the project. Of the 169 probands contacted, 132 (78\%) agreed to participate. Thirty-seven probands refused to contact their brothers. The reasons given were 1) the brother was not interested in participating, 2) the brother lived out of the country, 3) the proband was estranged from brother, or 4) the brother was in poor health. Furthermore, nine unaffected men declined when contacted by their sibling. One hundred eleven men $(90 \%)$ were contacted by interviewers and completed the telephone survey for a final response rate of $66 \%$. All protocols were reviewed and approved by institutional review board of The University of Michigan Medical School.

\section{Survey Instrument}

The current pilot investigation is limited to the unaffected brothers of men with prostate carcinoma who consented to participate in the PCGP and who agreed to complete a computer-assisted, telephone survey using BioDBx software (version 4.0; University of Michigan, Ann Arbor, MI, 2002). The survey, which is approximately 20 minutes in length, was designed primarily to assess the use of complementary and alternative medicines (CAMs), screening behavior, and risk perception among men presumed to be at an increased risk for developing prostate carcinoma. The prevalence of CAM use in this population will be reported in a forthcoming article. However, to illustrate the influence of risk perception and concern on health behaviors in these men, an evaluation of the relation between risk perception and current CAM use is included in the current investigation.

Respondents provided information regarding demographic and behavioral characteristics (education, marital status, household income, occupation, smoking history, and alcohol consumption). Self-reported race and age were obtained before survey administration. Participants also provided information concerning history of prostate-specific antigen (PSA) tests, digital rectal examinations (DREs), and prostate biopsies.

Finally, subjects were asked a series of 4 questions aimed to assess their short-term (10-year) and longterm (lifetime) absolute risk of developing prostate carcinoma. The measures, adapted from Diefenbach et al. ${ }^{8}$ and Lipkus et al., ${ }^{9}$ were constructed to assess risk perception and concern. Subjects were asked: "On a scale of 0 to 10 , where 0 is certain not to happen and 10 is certain to happen, how likely are you to get prostate carcinoma in the next 10 years / in your lifetime?" Men were also asked: "How concerned are you about getting prostate carcinoma in the next 10 years / in your lifetime?" The response anchors were a) not at all concerned, b) slightly concerned, c) somewhat concerned, d) concerned, and e) very concerned. The responses were then assigned numeric values on a 5-point Likert scale (1, not at all concerned; 5 , very concerned).

\section{Statistical Methods}

Data analysis was performed using SAS software (version 8.2; Cary, NC). Histograms were plotted to show the distribution of both short-term and long-term perceived prostate carcinoma risk and concern. Student $t$ tests were performed according to the Satterthwaite method to estimate differences in mean risk percep- 
TABLE 1

Sociodemographic Characteristics among Unaffected Brothers of Men with Prostate Carcinoma

\begin{tabular}{lc}
\hline Characteristics & No. (\%) \\
\hline Age (yrs) & \\
$<50$ & $33(29.7)$ \\
$50-60$ & $51(45.9)$ \\
$>60$ & $27(24.3)$ \\
Marital status & \\
Married & $94(86.2)$ \\
Not married & $15(13.8)$ \\
Education & \\
$<16$ yrs & $56(50.9)$ \\
$16+$ yrs & $54(49.1)$ \\
Household income & \\
$<\$ 50,000$ & $28(26.7)$ \\
\$50,000-\$99,000 & $38(36.2)$ \\
$\$ 100,000+$ & $39(37.1)$ \\
Family history & \\
One affected first-degree relative & $55(52.9)$ \\
$\geq 2$ affected first-degree relatives & $49(47.1)$ \\
Smoking status & \\
Current smoker & $15(13.5)$ \\
Nonsmoker & $96(86.5)$ \\
\hline
\end{tabular}

tion and concern among the participants. The tests compared selected demographic and behavioral characteristics, the number of relatives affected with prostate carcinoma, and age of the participants at the time of interview in relation to the age at diagnosis of their brother and their brother's current age. In families in which two or more brothers were diagnosed with prostate carcinoma, the subject's age was compared with the youngest of the affected siblings. Pearson correlation coefficients $(r)$ were calculated to evaluate the correlations among long-term and short-term risk perception, long-term and short-term concern, risk perception and concern, and measures of risk perception and concern with use of CAMs. Statistical significance was considered to be $P \leq 0.05$.

\section{RESULTS}

By design, all subjects in the current study had at least 1 brother living with prostate carcinoma and $47 \%$ of these men had $\geq 2$ affected first-degree relatives. Onehundred six (95\%) of the subjects were white and the remaining 5 subjects were black. The median age of the study participants was 53 years (range, 33-78 years; Table 1). Approximately $86 \%$ of respondents were married at the time of interview. The remaining subjects were either divorced $(9 \%)$ or single $(5 \%)$. A majority of men reported having attended college, with nearly $30 \%$ earning a postgraduate degree. The majority of subjects $(52 \%)$ also reported household

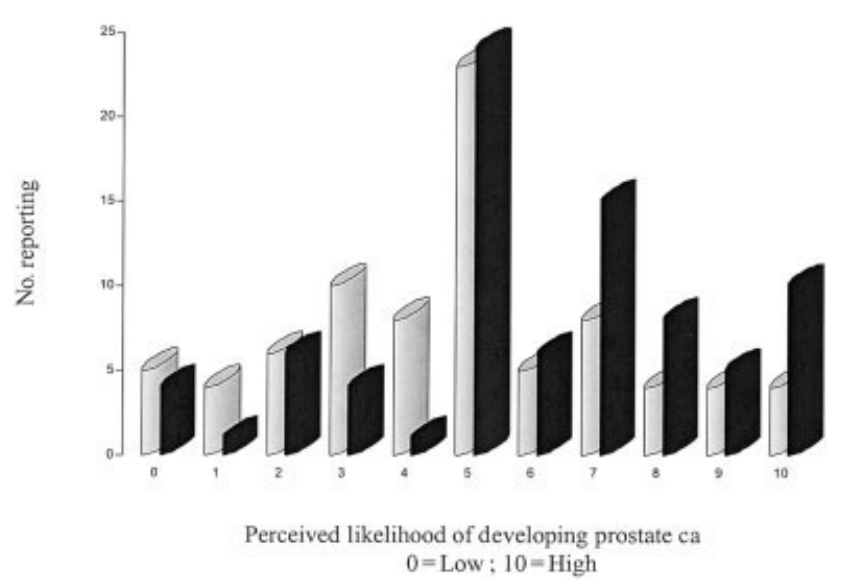

FIGURE 1. Risk perception in the brothers of men with prostate carcinoma (ca). Open squares: short-term risk; solid squares: long-term risk.

incomes of $\geq \$ 75,000$ annually. Sixty-two men (56\%) had smoked cigarettes at some point during their lifetime; however, only 15 men reported that they currently smoked. Among smokers, a majority of men smoked on average a pack of cigarettes or more per day. Among former smokers, the mean duration of time since they had last smoked was 19 years (data not shown).

The perceived likelihood of developing prostate carcinoma among the majority of participants was $\geq 50 \%$, corresponding to a score $\geq 5$ (Fig. 1). Longterm risk assessment was higher than short-term estimates. Similarly, $>50 \%$ of the subjects also reported being at least somewhat concerned about developing prostate carcinoma. However, concern was greater for lifetime risk of prostate carcinoma compared with concern over short-term risk (i.e., $>10$ years; Fig. 2). Measures of 10-year and lifetime risk perception were found to be highly correlated $(r=0.74 ; P<0.0001)$, as were short-term and long-term concern $(r=0.85 ; P$ $<0.0001$; Table 2). Responses to risk perception questions also were found to be significantly correlated with reported levels of concern $(r=0.62$ and $r=0.53$, respectively, for 10-year and lifetime measures).

Married men were not as concerned about an impending diagnosis of prostate carcinoma compared with unmarried men. However, the estimates with regard to the likelihood of developing the disease were similar (Table 3). Level of education was unrelated to reported levels of concern and risk perception.

The mean age of survey participants (54.4 years) was slightly younger than that of their affected brothers (55.1 years) (Table 4). Men who were younger than their affected brother reported a significantly higher estimate of short-term and long-term risk of prostate 


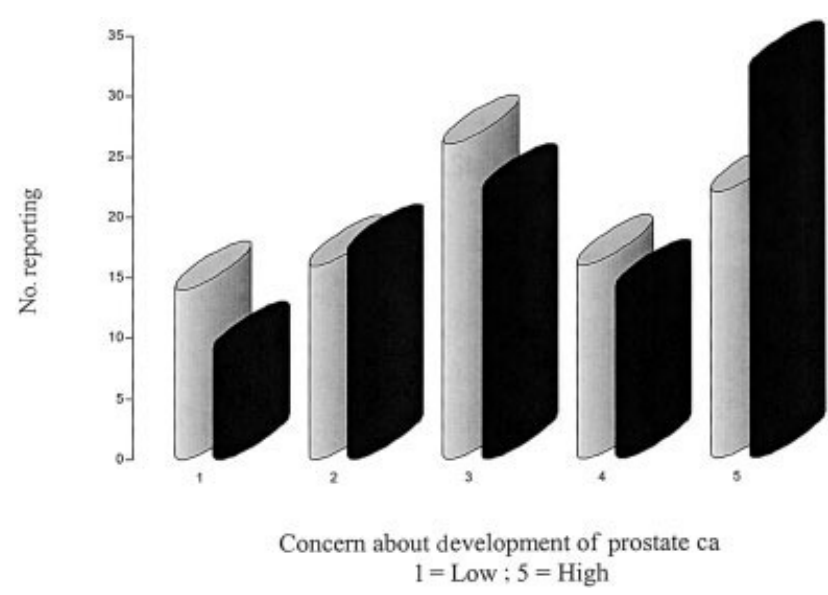

FIGURE 2. Concern about the development of prostate carcinoma (ca) in unaffected brothers of men with prostate carcinoma. Open squares: short-term concern; solid squares: long-term concern.

TABLE 2

Correlations between Measures of Short-Term (10-Year) and LongTerm (Lifetime) Risk Perception and Concern

\begin{tabular}{|c|c|c|c|c|}
\hline \multirow[b]{3}{*}{ Characteristics } & \multicolumn{4}{|c|}{ Pearson correlation coefficient } \\
\hline & \multicolumn{2}{|c|}{$\begin{array}{l}\text { Likelihood of developing } \\
\text { prostate carcinoma }\end{array}$} & \multicolumn{2}{|c|}{$\begin{array}{l}\text { Concern about } \\
\text { developing prostate } \\
\text { carcinoma }\end{array}$} \\
\hline & $\begin{array}{l}\text { In next } 10 \\
\text { yrs }\end{array}$ & $\begin{array}{l}\text { During } \\
\text { lifetime }\end{array}$ & $\begin{array}{l}\text { In next } 10 \\
\text { yrs }\end{array}$ & $\begin{array}{l}\text { During } \\
\text { lifetime }\end{array}$ \\
\hline \multicolumn{5}{|c|}{ Likelihood of developing prostate carcinoma } \\
\hline In next 10 yrs & - & 0.74 & 0.62 & - \\
\hline During lifetime & $0.74^{\mathrm{a}}$ & - & - & 0.53 \\
\hline \multicolumn{5}{|c|}{ Concern about developing prostate carcinoma } \\
\hline In next 10 yrs & 0.62 & - & - & 0.85 \\
\hline During lifetime & - & 0.53 & 0.85 & - \\
\hline
\end{tabular}

carcinoma compared with brothers who were older than their affected sibling $(P<0.0001$ and 0.0002 , respectively). The differences in risk perception were found to be slightly more apparent when the subject was younger than their brother at the time of diagnosis of prostate carcinoma. Likewise, younger brothers also reported significantly higher levels of concern about developing prostate carcinoma, both in the next 10 years and during their lifetime, compared with older brothers. Estimates of personal risk and reported levels of concern were uniformly higher among men with two or more affected first-degree relatives compared with men whose brother was the only firstdegree relative with prostate carcinoma. However, the differences were not statistically significant (Table 4).
Nevertheless, risk perception and concern among unaffected brothers were similar between the 21 families with $\geq 3$ confirmed affected men and the 66 families with $<3$ affected family members (data not shown).

The association between risk perception/concern and use of CAMs was assessed to highlight how these factors may affect health behaviors. Correlations between the perceived probability of developing prostate carcinoma and CAM use were stronger for short-term than for long-term risk (Table 5). When the CAMs were limited to only the vitamins and supplements suggested to be beneficial for prostate health in general or those that may possess cancer chemopreventive properties, use also was found to be more highly correlated with short-term versus long-term risk perception. Lifetime concern was more highly correlated with use of CAMs compared with concern about a diagnosis within 10 years ( $r=0.65$ vs. 0.45 ). However, when the analysis was restricted to include only the prostaterelated CAMs, concern about developing prostate carcinoma in the next 10 years was found to be more strongly correlated with use compared with lifetime concern ( $r=0.96$ vs. 0.73 ).

\section{DISCUSSION}

The results of the current study demonstrate that most men with a family history of prostate carcinoma in a first-degree relative were concerned about a potential diagnosis of prostate carcinoma. This concern was found to be higher for diagnosis over the long term compared with diagnosis over the short term. Furthermore, a majority of men presumed they had a $\geq 50 \%$ chance of developing prostate carcinoma at some point during their lifetime. Given their family history, a comparison with the estimated probability of prostate carcinoma would suggest that these men are accurately assessing their personal risk. The likelihood of developing prostate carcinoma has been estimated in the general population to be approximately $16.7 \%$ or 1 in 6 men. ${ }^{10}$ Nevertheless, the estimated lifetime risk of prostate carcinoma in a man with an affected brother is $56 \%$ (calculated by multiplying the lifetime probability statistic by the relative risk associated with an affected brother as determined by a recent metaanalysis [3.37]). ${ }^{2}$ Population-based studies of risk perception suggest that men tend to overestimate their personal risk of developing prostate carcinoma. ${ }^{11,12}$ Clarke et al. ${ }^{11}$ reported that in a study of 200 men age 45-60 years, the mean estimate of the probability of developing prostate carcinoma was $25 \%$, which is higher than the predicted likelihood (16.7\%). ${ }^{11}$ Data from the New York Behavioral Risk Factor Surveillance System indicated that approximately $40 \%$ of men sur- 
TABLE 3

Selected Sociodemographic Characteristics and Risk Perception in Unaffected Brothers of Men with Prostate Carcinoma

\begin{tabular}{|c|c|c|c|c|}
\hline \multirow[b]{2}{*}{ Characteristics } & \multicolumn{2}{|c|}{$\begin{array}{l}\text { Mean reported perception of likelihood of } \\
\text { developing prostate carcinoma }\end{array}$} & \multicolumn{2}{|c|}{$\begin{array}{l}\text { Mean reported level of concern about } \\
\text { developing prostate carcinoma }\end{array}$} \\
\hline & In next 10 years & During lifetime & In next $10 \mathrm{yrs}$ & During lifetime \\
\hline Married & $4.70(73)^{\mathrm{a}}$ & $5.96(75)$ & $3.04(83)$ & $3.34(83)$ \\
\hline Not married & $5.50(8)$ & $5.78(9)$ & 4.18 (11) & 4.36 (11) \\
\hline$P$ value & 0.3954 & 0.8126 & 0.006 & 0.005 \\
\hline College degree or greater & $4.88(40)$ & $5.91(42)$ & $3.24(45)$ & $3.56(45)$ \\
\hline Less than a college degree & $4.58(40)$ & $5.90(41)$ & $3.06(48)$ & $3.33(48)$ \\
\hline$P$ value & 0.5992 & 0.9968 & 0.5218 & 0.4384 \\
\hline
\end{tabular}

TABLE 4

Risk Perception and Concern in Unaffected Brothers of Men with Prostate Carcinoma: Age of Respondent in Relation to Age of Proband and Extent of Prostate Carcinoma Family History

\begin{tabular}{|c|c|c|c|c|}
\hline \multirow[b]{2}{*}{ Characteristics } & \multicolumn{2}{|c|}{$\begin{array}{l}\text { Mean reported perception of likelihood } \\
\text { of developing prostate carcinoma }\end{array}$} & \multicolumn{2}{|c|}{$\begin{array}{l}\text { Mean reported level of concern about } \\
\text { developing prostate carcinoma }\end{array}$} \\
\hline & In next 10 yrs & During lifetime & In next 10 yrs & During lifetime \\
\hline Respondent is younger than affected brother & $5.73(44)^{\mathrm{a}}$ & $6.74(46)$ & $3.55(53)$ & $3.91(53)$ \\
\hline Same age or older than affected brother & $3.16(32)$ & $4.49(33)$ & $2.53(36)$ & $2.72(36)$ \\
\hline$P$ value & $<0.0001$ & 0.0002 & 0.0009 & $<0.0001$ \\
\hline Respondent is younger than affected brother at time of diagnosis & $6.15(33)$ & $7.00(35)$ & $3.86(37)$ & $4.22(37)$ \\
\hline Same age or older than affected brother at time of diagnosis & $3.49(43)$ & $4.84(44)$ & $2.62(52)$ & $2.87(52)$ \\
\hline$P$ value & $<0.0001$ & 0.0001 & $<0.0001$ & $<0.0001$ \\
\hline Respondent has two or more affected first-degree relatives & $5.10(31)$ & $6.39(33)$ & $3.38(37)$ & $3.68(37)$ \\
\hline One affected first-degree relative & $4.25(43)$ & $5.43(44)$ & $2.92(50)$ & $3.20(50)$ \\
\hline$P$ value & 0.1576 & 0.1109 & 0.1207 & 0.1116 \\
\hline
\end{tabular}

veyed in 1997 perceived their risk of prostate carcinoma to be "medium" and "high." It is interesting to note that this estimate excludes $30 \%$ of the sample that reported they could not estimate their personal risk. $^{12}$

Although studies of risk perception in men with a family history of prostate carcinoma demonstrate that they generally are aware of their heightened risk, there is always a subset of individuals who underestimate their personal risk. Cormier et al. ${ }^{13}$ reported that $51 \%$ of men with a family history of prostate carcinoma in a first-degree relative believed that their probability of developing the disease was greater than average. Moreover, although most men $(76 \%)$ knew that a positive family history was a risk factor for prostate carcinoma, $38 \%$ of these men reported their own risk to be the same as or less than the average man. Similarly, Miller et al. $^{14}$ observed that $43 \%$ of the first-degree relatives of men with prostate carcinoma believed their risk to be the same as or lower than the general population.

A number of studies have assessed the relation among risk perception, adherence to screening, and interest in genetic testing between men and women with a family history of cancer. ${ }^{15-25}$ However, to our knowledge very few have evaluated specific factors that influence risk perception and concern in those with an inherited predisposition, particularly with respect to prostate carcinoma.

We observed that unmarried men were more concerned about prostate carcinoma than their married counterparts, yet personal risk assessments were similar. It may be that spouses provide a sense of security and reduce concern about potential health problems. Unmarried men likely do not have the same social support, which may compound the existing anxiety over a future diagnosis of prostate carcinoma.

To our knowledge, the current study is the first in 
TABLE 5

Correlations between CAM Use and Risk Perception and Concern

\begin{tabular}{lll}
\hline & \multicolumn{2}{c}{ Pearson correlation coefficient $(\boldsymbol{P}$ value $)$} \\
\cline { 2 - 3 } & $\begin{array}{l}\text { Total no. of } \\
\text { CAMs ever } \\
\text { used }\end{array}$ & $\begin{array}{l}\text { Total no. of } \\
\text { prostate-related } \\
\text { CAMs }^{\mathbf{a}} \text { ever used }\end{array}$ \\
Characteristics & \\
\hline Likelihood of developing prostate carcinoma \\
In next 10 yrs & $0.9087(0.01)$ & $0.8730(0.02)$ \\
During lifetime & $0.4684(0.08)$ & $0.4280(0.09)$ \\
Concern about developing prostate carcinoma & \\
In next 10 yrs & $0.4533(0.08)$ & $0.9627(0.0004)$ \\
During lifetime & $0.6562(0.05)$ & $0.7351(0.04)$ \\
\hline
\end{tabular}

CAM: complementary and alternative medicine.

a Vitamins A, C, and E; beta-carotene; flaxseed oil; finasteride; male hormones; green tea; selenium; magnesium; soy, and saw palmetto.

the literature to assess birth order in relation to a brother diagnosed with prostate carcinoma and risk perception among unaffected family members. We observed that subjects who were younger than their affected brother both at the time of interview and at diagnosis were more concerned and their perception of risk was higher than men who were older than their affected brother. This finding is particularly interesting because we know that older age is a strong predictor of risk. Among all men, regardless of their genetic predisposition, the incidence of prostate carcinoma increases dramatically with age (approximately $1 \%$ per year after age 50 years). Seventy percent of cases are reportedly diagnosed after age 65 years. ${ }^{10}$ We are uncertain as to why older brothers are not as concerned about the possibility of an impending diagnosis. It may be that men who are older than their affected brother could mistakenly assume that they have passed the risk phase for development of prostate carcinoma and could consider themselves to be no longer at risk. An alternative explanation may be that older brothers are not as concerned about a diagnosis in the future, assuming that they are unlikely to die of the disease because of the relatively indolent course of most cases of prostate carcinoma. Most men diagnosed after age 70 years will die of conditions unrelated to their prostate carcinoma. ${ }^{26}$

Men with two or more affected members of their nuclear family were more concerned and their perceived risk higher than men whose affected brother was the only first-degree relative affected. The current study results are comparable to results of what to our knowledge is the only other study of predictors of cancer worry and risk perception among men with a positive family history of prostate carcinoma. Bratt et al. ${ }^{22}$ observed perceived risk to be positively correlated with the number of affected relatives $(r=0.23 ; P$ $=0.001$ ) and with the number of relatives dying of prostate carcinoma $(P=0.01)$. The number of deaths among relatives due to prostate carcinoma also was found to be correlated with cancer worry.

In the current study, reported levels of both shortterm and long-term concern were found to be significantly correlated with the estimates of personal risk. Short-term estimates of both measures were found to be highly correlated with long-term estimates. These findings are consistent with similar studies in the literature on prostate and breast carcinoma. ${ }^{9,22}$ Bratt et $\mathrm{al}^{22}$ reported that subjects who overestimated their personal risk of prostate carcinoma also reported that worry over cancer interfered with their lives on a daily basis. Lipkus et al. ${ }^{9}$ found that worry about breast carcinoma was positively correlated with risk perception among women with and without a family history of breast carcinoma.

Finally, the observed relation between risk perception and concern with CAM use in the current study shows that heightened concern and perceived risk can translate into health behaviors that are intended to prevent future cancer occurrence. Furthermore, the results of the current study suggest that short-term risk perception and concern may be a better predictor of health-related behaviors than perceived risk and worry about prostate carcinoma development at some point during one's lifetime.

There are limitations in the design of the current study that require careful interpretation of the findings. The small sample of subjects may limit our ability to detect some findings of potential statistical significance. Moreover, because $95 \%$ of the study population was white, we could not evaluate potential racial differences in risk perception and concern. In addition, $>50 \%$ of subjects in the current study reported household incomes of $>\$ 75,000$ annually and were well educated. Therefore, the current study results may not be generalizable to populations in lower socioeconomic strata. Furthermore, it is possible that, as participants in a genetic study, these men are more knowledgeable about their personal risk of prostate carcinoma. This would limit the generalizability of these findings to men in the general population or to men with a family history, but who are unrelated to anyone participating in a genetic study. Participants in the current study have not received any specific information regarding the personal risk of prostate carcinoma. Subjects may be knowledgeable of the finding that family history is a risk factor for prostate carcinoma. If this were true, one might expect that these 
men would report their risk of developing prostate carcinoma to be higher than the average man. Yet, this knowledge does not necessarily translate into accurate risk assessment, as supported by the results by Cormier et al. ${ }^{13}$ Information concerning the number of affected relatives was not reported by participants in the current survey. Rather, it was provided by the proband and confirmed by PCGP research personnel. This may explain the inconsistency in findings relating risk perception and concern to the number of affected first-degree family members versus the total number of affected relatives in a family. Although it is likely that unaffected men would know the disease status of close family members, it also is plausible that they are unaware of the health conditions of more removed relatives. Men with prostate carcinoma are more likely to be knowledgeable of other family members who have the same disease. Finally, once permission was obtained to contact potential subjects, the response rate among the unaffected brothers was high (90\%). However, many of the probands would not allow us to contact their brother, which reduced the overall response rate $(66 \%)$ and introduced the possibility of selection bias due to nonparticipation.

The results of the current study indicate that a majority of men with a family history of prostate carcinoma estimate their personal risk of developing prostate carcinoma to be $\geq 50 \%$ and are concerned about an impending diagnosis. Risk perception and concern about a potential diagnosis of prostate carcinoma appear to be influenced by marital status, the number of affected first-degree relatives, and the age of the unaffected man relative to his affected brother. The latter point may have important implications for prostate carcinoma education and early detection. It is critical to recognize that prostate carcinoma is a lateonset disease that provides an important window of opportunity for potential clinical intervention through early detection and modification of risk. Larger studies are clearly needed, including those of men representing more diverse populations, to more fully characterize the determinants of risk perception and concern for prostate carcinoma because these perceptions impact important behaviors, including CAM use to improve prostate health.

\section{REFERENCES}

1. Jemal A, Murray T, Samuels A, Ghafoor A, Ward E, Thun MJ. Cancer statistics 2003. CA.2003;53:5-26.

2. Zeegers MPA, Jellema A, Ostrer H. Empiric risk of prostate carcinoma for relatives of patients with prostate carcinoma: a meta-analysis. Cancer. 2003;97:1894-1903.
3. Steinberg GD, Carter BS, Beaty TH, Childs B, Walsh PC. Family history and risk of prostate cancer. Prostate. 1990;17: 337-347.

4. Whittemore AS, Wu AH, Kolonel LN, et al. Family history and prostate cancer risk in black,white and Asian men in the United States and Canada. Am J Epidemiol. 1995;141:732740 .

5. Hayes RB, Liff JM, Pottern LM, et al. Prostate cancer risk in US blacks and whites with a family history of cancer. Int $J$ Cancer. 1995;60:361-364.

6. Lesko SM, Rosenberg L, Shapiro S. Family history and prostate cancer risk. Am J Epidemiol. 1996;144:1041-1047.

7. Lichtenstein P, Holm NV, Verkasalo PK, et al. Environmental and heritable factors in the causation of cancer. $N$ Engl J Med. 2000;343:78-136.

8. Diefenbach MA, Weinstein ND, O'Reilly JO. Scales for assessing perceptions of health hazard susceptibility. Health Educ Res. 1993;8:181-192.

9. Lipkus IM, Kuchibhatla M, McBride CM, et al. Relationships among breast cancer perceived absolute risk, comparative risk and worries. Cancer Epidemiol Biomarkers Prev. 2000; 9:973-975.

10. Ries LAG, Eisner MP, Kosary CL, et al. SEER cancer statistics review 1975-2000. Bethesda, MD: National Cancer Institute, 2003.

11. Clarke VA, Lovegrove H, Williams A, Machperson M. Unrealistic optimism and the health belief model . J Behav Med. 2000;23:367-376.

12. McDavid K, Melnik TA, Derderian H. Prostate cancer screening trends of New York state men at least 50 years of age, 1994 to 1997. Prev Med. 2000;31:195-202.

13. Cormier L, Kwan L, Reid K, Litwin MS. Knowledge and beliefs among brothers and sons of men with prostate cancer. Adult Urol. 2002;59:895-900.

14. Miller SM, Diefenbach MA, Kruus LK, Watkins-Bruner D, Hanks GE, Engstrom PF. Psychological and screening profiles of first degree relatives of prostate cancer patients. $J$ Behav Med. 2001;24:247-258.

15. Wolf AMD, Philbrick JT, Schorling JB. Predictors of interest in prostate-specific antigen screening and the impact of informed consent: what should we tell our patients? Am J Med. 1997;103:308-314.

16. Demark-Wahnefried W, Strigo T, Catoe K, et al. Knowledge, beliefs, and prior screening behavior among blacks and whites reporting for prostate cancer screening. Adult Urol. 1995;46:346-351.

17. Miesfeldt S, Jones SM, Cohn W, et al. Men's attitudes regarding genetic testing for hereditary prostate cancer risk. Adult Urol. 2000;55:46-50.

18. Diefenbach MA, Schnoll RA, Miller SM, Brower L. Genetic testing for prostate cancer. Cancer Pract. 2000;8:82-86.

19. Diefenbach MA, Miller SM, Daly MB. Specific worry about breast cancer predicts mammography use in women at risk for breast and ovarian cancer. Health Psychol. 1999;18:532536.

20. Lipkus IM, Iden D, Terrenoire J, Feaganes JR. Relationships among breast cancer concern, risk perceptions, and interest in genetic testing for breast cancer susceptibility among African American women with and without and family history of breast cancer. Cancer Epidemiol Biomarkers Prev. 1999;8:533-539. 
21. Carney PA, Harwood BG, Weiss JE, Eliassen MS, Goodrich ME. Factors associated with interval adherence to mammography screening in a population-based sample of New Hampshire women. Cancer. 2002;95:219-227.

22. Bratt O, Damber JE, Emanuelsson M, et al. Risk perception, screening practice and interest in genetic testing among unaffected men in families with hereditary prostate cancer. Eur J Cancer. 2000;36:235-241.

23. Halabi S, Skinner CS, Samsa GP, Strigo T, Crawford YS, Rimer BK. Factors associated with repeat mammography screening. J Fam Pract. 2000;49:1104-1112.
24. Steginga SK, Occhipinti S, McCaffrey J, Dunn J. Men's attitudes toward prostate cancer and seeking prostate-specific antigen testing. J Cancer Educ. 2001;16:42-45.

25. Cormier L, Reid K, Kwan L, Litwin MS. Screening behavior in brothers and sons of men with prostate cancer. J Urol. 2003;169:1715-1719.

26. Albertsen PC. Clinical epidemiology: incidence rates, databases, age and co-morbidity. In: Kantoff PW, Carroll PR, D'Amico AV, editors. Prostate cancer: principles and practice. Philadelphia: Lippincott Williams and Wilkins, 2002: 178-194. 